\title{
Study on Human Resource Planning of Dongguan Zhou Liang Communication Science and Technology Limited Company
}

\author{
Ningning Yan $^{1,}$ a * \\ ${ }^{1}$ School of Business Administration, JingDeZhen Ceramic Institute, Jiangxi Province, China \\ asemail2008@163.com
}

\begin{abstract}
Keywords: Human resource; Human resource planning; Human resources management; Strategic on human resources; Management efficiency
\end{abstract}

\begin{abstract}
Human resource planning efficiency is directly related to the level of the enterprise human resource management job performance, it is the enterprise core competitiveness the key elements, reasonable human resource planning can improve the enterprise human resources utilization and the management efficiency of the enterprise and management efficiency. First, this paper analyzes the human resources management of the company a few questions: position analysis and design of the more obscure positioning post; personnel recruiting and staffing optional sex is bigger; personnel training and human development not enough jobs in place; evaluation and assessment work not enough science; compensation and benefits management system is relatively single. Once again, the company human resources planning, put forward to control gross, optimize a structure; norm system of human resources, build quality model and four teams of construction planning focus, at the same time, enterprise's human resources business planning; proposed the implementation of human resources planning measures, to ensure the implementation of the plans. Finally, discusses the human resource planning system in the implementation of the security measures, including strengthening human resource planning consciousness, improve human resource planning security system, clear human resource planning positioning and the emphasis on human resources planning communication and feedback.
\end{abstract}

\section{Introduction}

With economic and social development and human resource planning becomes more and more important, because human resource planning is reasonable or not is related to organizational performance and perfect, and is the key elements to construct the core competitiveness of enterprises. Reasonable human resource planning can improve the enterprise human resource utilization rate and enterprise's operation efficiency, management efficiency, but also help to establish the enterprise system of post responsibility, "everything was tubes, everyone has dedicated" situation, thus greatly enhance inter organizational coordination and cooperation. And unreasonable human resources planning is likely to cause unknown powers and responsibilities of the chaos, cannot make full use of enterprise human resources, optimizing the structure of enterprise personnel; on the other hand reduce the operational efficiency of enterprises and the input-output ratio, and may even lose some important development opportunities. From the point of view of our current situation in China, small and medium enterprises and become the main force of economic development, due to the enterprises of different sizes, different types of its own characteristics are also different, the instability of the internal structure of small and medium enterprises in the susceptible to the influence of environmental factors.

From the point of view of theory, this paper studies how in the small and medium enterprises should pay more attention to develop in line with the overall development strategy of human resources planning, including the development and management of human resources, personnel structure optimization to achieve stable internal structure. It pays more attention to the rationality of human resources planning, normative and practical, so as to ensure the normal demand of human resources.

From the point of view of practice, this paper intends to Dongguan Zhou Liang human resources planning studies communication technology Co., Ltd. as an example, summarizes the rational planning 
of human resources for the enterprise management, improve the effectiveness of, and that it was not by experience and theory to from their own reality, seeking truth from facts to develop in line with the actual enterprise human resource planning, so as to make it exert the maximum role and optimize personnel structure, improve operational efficiency, build the core competitiveness. The purpose of this research is to provide a method to solve the problem of internal human resources, which is of great practical significance.

\section{The Problems of Human Resources Planning in Zhou Liang Company}

The accelerated development of the world economy, between enterprise competition intensifies, enterprises should want to remain invincible in the fierce competition in the market must be correct look at yourself, for the foreseeable future, construct core competition and formulate a long-term development strategy, the enterprise human resources management does not allow to ignore. Because of the human resources management related to the enterprise's operating efficiency, product input and output ratio and the rate of profit and so on, also the management of human resources must associated with all stages of enterprise development strategy, do everything for the development of enterprises. In the case of a company, now the situation of human resource management is not ideal, its human resource management just pure arrangements for the work, and no contact of each stage and Department of enterprise development plan, is just a part of isolated, not as a whole help improve operational efficiency of the enterprise, product output to input ratio raise, this is not the practice of global will cause post the number of enterprises that do not meet the actual needs, work efficiency is low redundancy, employees cannot carry out their duties, chaotic management situation, also unable to give full scope to the talents, rational use and allocation of talent is very easy to cause the enterprise brain drain, the decline in core competitiveness. Research and analysis of the above situation caused by the company's deep reason is that the implementation of its human resources planning system has some obstacles:

One is the support of senior management of enterprises is not enough. This is the enterprise human resources planning system cannot be a better implementation of the key factors. Attitude determines the results, on the business concerned enterprise top leadership staff determines the success in business, when the leader believes that enterprise human resources management departments just affairs department and enterprise overall development strategy is not related, enterprise human resources management is really just receiving department of administrative affairs, isolated associated not with the enterprise's overall development and permeates, below the staff ignored more easily lead to low efficiency, personnel structure of the chaotic situation, so to want to effective implementation of the enterprise human resources planning system must be paid more attention to by the top leaders of the. Specifically: in the enterprises to actively carry out the strategy of globalization, its main task can be divided into two directions: the first is the globalization of product sales, followed by the globalization of manufacturing products, the two aspects in later in the implementation process because of different degree of concern to supervisors of personnel and results to differ materially. In terms of sales of products, because senior managers are highly valued while making the long-term strategy for the enterprises in the development of the globalization, so shortly after successfully occupied the international market share, to enter the international market to lay a solid foundation. However, in the manufacture of products, the result is not satisfactory. Internal longitudinal body because the lack of effective communication, the overall strategy of the enterprise information could not be delivered, resulting in the following agency staff asunder, deployment of personnel difficulties, slow and personnel structure of rigid these have a great impact on the enterprise product production efficiency and the globalization strategy execution.

The second is not to meet the needs of the implementation of the lower level managers. Because the upper level decision department managers do not understand the real situation of the lower executive body, it is easy to make the invalid management decision, so as to reduce the work efficiency and waste of enterprise resources. Specifically: as to promote the development of social economy and 
globalization, enterprises continue to grow and develop, the personnel structure is also gradually complicated, on the other hand the decision-making departments do not understand the specifications, types, grades lower execution departments and the related staff, the number of enterprises in the future so the human resources required for the calculation more difficult, due to strategic planning information can't communicate may also be caused by the conflict between departments, not coordination, causing friction and therefore should measure the demand actively make lower execution management in the enterprise specific human resources department, they are the most clear Department of human resource planning, talent specifications required, type, level and should carry out staff training programs, the only way to fully meet the needs of the lower. Line sector management needs, improve work efficiency, and correctly predict the future of the human resource needs of the enterprise.

The third is the foundation work of the company did not do a good job, internal no clear provisions about jobs, no position clear rights and responsibilities, competition condition caused by the responsibilities, powers and responsibilities unclear phenomenon. Appeared in the human resources management is chaotic situation, such as a job redundancies, overstaffing and another position of inadequate staffing; staffing difficulties, important positions difficult; lack of staff training, do not have sense of belonging to the enterprise; the enterprise staff recruitment channels narrow blind rejection of foreign talent, and so on, although the enterprise in try to formulate unified rules and regulations, but little effect, the reason is not found the main aspects of the principal contradiction.

Fourth is the method of human resource planning application should be optimized. Enterprise managers with method of pure theory to describe the survival state employees, including their concerns, such as appreciation raises; but some other uses data to monitor that employees in various departments within the enterprise between the horizontal and vertical flow, managers of their attention is management activities it is necessary to study the, and should therefore be to use a combination of the two methods, so as to fully do human resource planning.

Fifth is the human resource planning implementation difficult. Enterprise human resource planning requires integration of the enterprise's overall development strategy, job responsibilities and power, personnel specifications, type, level, employee's work attitude, enterprise rules and regulations, and to grasp the content is difficult, because inside qualitative things cannot be quantitatively expressed, also the enterprise human resources planning to consider all norms of human resources activities, and consistent with the plan for the development of the enterprise as a whole, each department.

To sum up, the enterprise human resources planning in the existence of such a problem, which also explains why the company personnel allocation, rational use and retention of talent is difficult. Traditional view is generally believed that talent loss is because enterprise is unable to provide generous treatment, high enough position, actually otherwise, people generally pay more attention to the realization of self-value. If the company has good organizational culture can provide learning progress of the platform for talent, made one learns by teaching atmosphere, the same can retain talent. Get success in small business capital is not strong is only good at human resources planning and make full use of, and combined with its own development strategy to achieve Renjinqicai, provide enough development space for employees, employees to help establish a positive world outlook, outlook on life, so to solve the enterprise in the presence of human resources is the key to do a good job in the enterprise human resources planning.

Through the investigation of the company's human resource allocation, we found that the company from 2003 to gradually improve the relevant rules and regulations of human resources, and try to move toward standardization and institutionalization. After further understanding, we found that there are still some obvious problems in human resource management, which is not conducive to the development of human resources planning.

To sum up, the company has some problems in human resource management, these issues are the basis of human resource planning. It is also due to the lack of human resources planning company, there is no systematic and global engaged in the work of human resource management, the headache medicine head, piecemeal, resulting in corporate human resources situation has been very chaotic. On 
the whole, the company's human resources work is still in the primary stage of the personnel management, lack of human resources demand and supply scientific prediction, lack of analysis and evaluation of the overall enterprise human resource management system, there is no scientific, reasonable and perfect human resource planning system from the strategic height to guide the company's human resources management work, resulting in a human resources job analysis, recruitment, staffing, training, assessment, evaluation, remuneration, welfare work has appeared in some problems, the company's human resources work not with the overall strategy of the company a consistent and coordinated, which the company toward globalization is extremely unfavorable. From this point of view, human resources planning in the company's business is very important.

\section{The Necessity of Human Resource Planning in Zhou Liang Company}

The necessity and importance of human resources planning is to enable enterprises to obtain appropriate employees at the appropriate time, and ultimately to achieve effective allocation of human resources. Specifically, the human resources planning objectives include four aspects: first, the development of human resources to provide planning.

The development of human resources planning, including human resource supply and demand forecast, human resources, human resources training program, the three of which rely on each other, mutual support. Human resource planning in addition to analysis the current corporate human resources, but also the future of the enterprise human resources supply and demand situation make forecasts, in order to facilitate the enterprise in the full understanding on the basis of the current status of human resources of the enterprise in the future allocation of human resource to make effective plans. At the same time, but also for enterprises to develop effective human resources training plan. Therefore, human resource planning is the basis of human resource management. Two is to improve the efficiency of human resources use.

The allocation efficiency of human resources is not high in many enterprises. A considerable part of the business of post setting unreasonable, often some people work burden is overweight, and another part of people work too easy; some people lack to assume corresponding jobs, another part is excess capacity, failed to develop effectively. Human resource planning can help enterprises to improve these conditions, improve the efficiency of human resources utilization, enhance the rationality of the position, and through human resources planning to promote enterprise and employee personal development needs. Three is to promote the development of the organization. As a basic business unit, the essential characteristic of the enterprise requires the enterprise to pursue the maximization of the reasonable profit, also requires that the enterprise can obtain the living space in the intense market competition. And this is bound to rely on the effective use of human resources and access to this important factor. It is in the right time, the right position to use the right staff. At the same time, makes the enterprise in the face of the external environment changing keep dynamic balance of the human resources, to meet the enterprises of various human resources quantity, quality, structure and the level of effective demand and promote the realization of the development objectives of the organization. This is the goal and significance of human resources planning. Four is to reduce the cost of human resources.

There are many factors that affect the cost of human resources, such as human resource recruitment costs, operating costs of human resources system, technical personnel ability, management ability, the level of workers, educational level and so on. Human resource planning can help enterprises effective analysis of existing human resources distribution and structure and the redundancy of human resources for a reasonable balance and find out the influence factors of human resource management, and supply and demand of human resources make scientific prediction, help enterprises to carry out on human resources management, play all the functions of human resource, reduce the ratio of human resources in the total cost of, and ultimately improve the ratio of enterprise human resource input and output. 


\section{Environmental Analysis of Zhou Liang Company Human Resource Planning}

Although domestic communications in the low-end market competition is unusually intense, and excess capacity resulting in a continued decline in industry profits, but high-end positioning of the communications industry supporting engineering due to its high quality requirements and need to the participating companies have highly coordinated team cooperation ability, so access to the high threshold. Company will main business choice in this regard, avoid the disorderly competition in the communication in the low-end market, itself in the design and production of both certain advantages, thus able to maintain a higher operating profit. At the same time, the opportunity to enter the market early, is conducive to the occupation of the market share. Therefore, although the company structure is not large, the scale of business is growing rapidly. Coupled with the world economy after the financial turmoil will gradually recover, the Chinese economy is also developing steadily, if the domestic and international economic situation does not change greatly, the company's operating results will be steadily increased.

According to the company's development strategy and the requirements of the target market, the company's human resources, whether from the quality of personnel or the management of the current situation, have failed to meet the demand. To achieve these goals, the company shall determine the corresponding human resources strategy, perfect organization, the cultivation of high quality management personnel; gradually improve the overall quality of the enterprise personnel, ensure the enterprise development needs of high-quality personnel, including a mating capacity provided the high need skilled front-line workers and technicians; strengthen personnel allocation rationality, emphasizing the rich flexibility and innovation of human resource management, the company's human resources from quantity and quality they can match with the realization of the strategic goal of the enterprise.

\section{Summary}

Based on the domestic and foreign research results of human resource planning based on analysis to the company as the research object, on the human resources planning were comprehensive and detailed analysis, points out the problems existing in the human resources planning, and in view of the problems existing in the construction of a new human resources planning system, guarantee and measures of human resources planning system were finally put forward.

\section{References}

[1] D. Quinn Mills, Planning with People in Mind, Harvard Business Review, July-August 1985, pp.97-105.

[2] Dyer, Lee. Human Resource Planning Guide, Random House, New York, 1986.

[3] Greer C.R et al Adapting Human Resource Planning in a Changing Environment, Human Resource Management, vo1.28.no.1, 1989,pp.105-124.

[4] Vetter, E.W. Manpower Planning for High Talent Personnel Bureau of Industrial Relations, University of Michigan, Ann, Arbor, 2007.

[5] Lawrence Sleiman. Human Resource Management: A Managerial Tool for Competitive Advantage, Thomson, a part of C engage Learning.2007. 